\title{
PHÃ̃U THUẠT NỘI SOI TOÀN BỘ KHÔNG CÓ ROBOT HỖ TRỢ, TIM ĐẬP VÁ THÔNG LIÊN NHĨ: KINH NGHIỆM Ở MỘT TRUNG TÂM
}

\author{
Đặng Quang Huy ${ }^{*}$, Phạm Thị Kim Lan ${ }^{*}$, Nguyễn Công Hưu ${ }^{*}$, \\ Truong Thanh Huoong ${ }^{* *}$, Lê Ngoc Thành*
}

\section{TÓM TĂT}

60 bệnh nhân (người lớn/trẻ nhỏ: 41/19; tuổi trung bình: $29,1 \pm 18,7$, từ 2 đến 61 tuổi)với chẩn đoán TLN thứ phát được lựa chọn vào nghiên cứu.Trong đó có 38 bệnh nhân (BN)TLN đơn thuần, 5 BNTLN kèm tĩnh mạch phổi (TMP) lạc chỗ bán phần, 17 BN TLN kèm hở van ba lá (VBL) nhiều. Đặt 3 trocar $5 \mathrm{~mm}$ và 1 trocar $12 \mathrm{~mm}$, chỉ thắt $\mathrm{TMC}$ trên, làm đầy khoang màng phổi bằng $\mathrm{CO} 2$, tim đập trong quá trình mổ. Lỗ thông được đóng bằng miếng vá nhân tạo hoặc khâu trực tiếp, TMP lạc chỗ được tạo đường hầm dẫn máu về nhĩ trái $(\mathrm{NT})$, sửa VBL bằng cách đặt vòng van hoặc phương pháp De Vega. Không có biến chứng liên quan phẫu thuật và tử vong sau mổ. Thời gian mổ và thời gian chạy máy trung bình lần lượt là 234,2 $\pm 54,3$ (phút) và $132 \pm 46,9$ (phút). BN được rút nội khí quản trong vòng 8 giờ đầu, dẫn lưu trong ngày đầu $<80 \mathrm{ml}$. Ngày thứ 4 sau mổBN không cần dùng thuốc giảm đau và trở về với sinh hoạt bình thường sau mổ 1 tuần. Phẫu thuật NSTB vá TLN tim đập là phương pháp an toàn, người bệnh hồi phục sớm, sẹo mổ có giá trị thẩm mỹ cao đặc biệt ở phụ nữ và trẻ gái.

Tù khóa: Thông liên nhĩ, phẫu thuật nội soi toàn bộ, tim đập, robot.

\section{I. ĐẶT VẤN ĐỀ}

Thông liên nhĩ là một trong số những bệnh TBS thường gặp nhất, chiếm từ $6-10 \%$ tổng số các dị tật TBS. Hơn 20 năm trở lại đây, tim mạch can thiệp là lựa chọn hàng dầu tại hầu hết các quốc gia trên thế giới với nhiều ưu điểm. $[1,2]$ Mặc dù vậy vẫn còn nhiều dạng TLN không bịt được dù cũng như nhiều biến chứng lâu dài của bịt dù TLN được ghi nhận.[2, 3]Nhiều năm trở lại đây, có nhiều báo cáo về áp dụng PT NSTB với sự hỗ trợ của hệ thống robot Da Vinci trong điều trị bệnh TLN đem lại kết quả rất tốt với thời gian hồi phục sớm và sẹo mổ có tính thẩm mỹ cao.[4-6] Tuy vậy chi phí đào tạo và chi phí phẫu thuật cao là rào cản lớn cho việc ứng dụng rộng rãi kỹ thuật hiện đại này ở những nước đang phát triển. Trên thế giới chưa có nhiều báo cáo về NSTB không cần hỗ trợ của robot để đóng TLN, đặc biệt ở trẻ nhỏ. Trong nghiên cứu này, chúng tôi báo cáo kinh nghiệm áp dụng NSTB sửa chữa bệnh TLN không có robot hỗ trợ qua 4 lỗ trocar nhỏ tại trung tâm của chúng tôi.

\section{II. ĐỐI TƯợNG VÀ PHƯƠNG PHÁP NGHIÊN CÚU}

\subsection{Lựa chọn bệnh nhân}

Trong khoảng thời gian từ tháng 5/2016 đến tháng 9/2017, 60 BN TLN lỗ thứ phát

* Trung tâm tim mach, Bệnh viện E

** Khoa nhi, viện tim mạch quốc gia, Bệnh viện Bạch Mai Nguoòi chịu trách nhiệm khoa học: GS.TS. Lê Ngọc Thành Ngày nhận bài: 01/10/2017 - Ngày Cho Phép Đăng: 05/10/2017 Phản Biện Khoa học: GS.TS. Bùi Đức Phú PGS.TS. Đặng Ngọc Hùng 
(bao gồm: $38 \mathrm{BN}$ TLN đơn thuần, $5 \mathrm{BN}$ TLN kèm TMP lạc chỗ bán phần, 17 BN TLN kèm hở VBL nhiều) được lựa chọn và điều trị bằng phương pháp phẫu thuật NSTB không có robot hỗ trợ, tim đập.

Đối tượng lựa chọn bao gồm cả người lớn và trẻ nhỏ với những tiêu chuẩn lựa chọn gồm: (1) chẩn đoán TLN lỗ thứ phát đơn thuần, TLN thể xoang tĩnh mạch, TLN kèm theo TMP lạc chỗ bán phần, TLN kèm theo sửa VBL; (2) cân nặng $>13 \mathrm{~kg}$. Tất cả $\mathrm{BN}$ được siêm âm doppler kiểm tra tình trạng động mạch $(\mathrm{DM})$ chậu đùi trước mổ. Những trường hợp xơ vữa hẹp ĐM chậu đùi, kích thước ĐM đùi quá nhỏ không thiết lập được tuần hoàn ngoại vi bị loại ra khỏi nghiên cứu. BN TLN lỗ tiên phát hoặc TLN kèm bệnh lý khác không được lựa chọn.

\section{Bảng 1: Các thông số nhân trắc học và thông số trước mổ (n=60)}

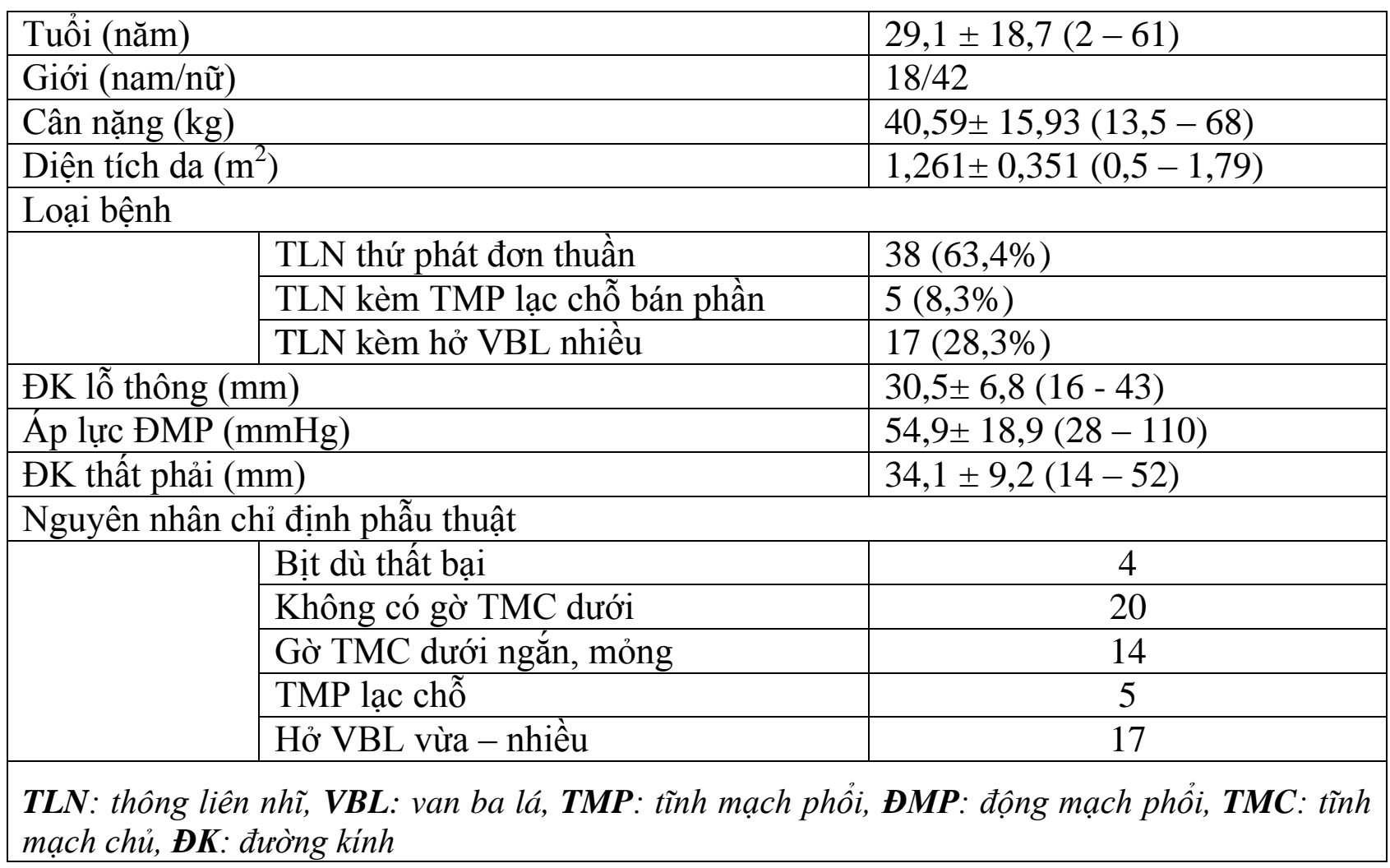

Các thông số nhân trắc học (tuổi, cân nặng, diện tích da, kích thước lỗ thông) trước mổ, các đặc điểm về bệnh học và nguyên nhân chỉ định mổ được trình bày trong Bảng 1. Phương pháp PT được hội đồng khoa học bệnh viện thông qua và được sự đồng thuận của gia đình $\mathrm{BN}$.

\subsection{Phương pháp phẫu thuật}

$\mathrm{BN}$ được gây mê bằng ống nội khí quản một nòng. Bác sĩ gây mê đặt catheter tĩnh mạch (TM) trung ương vào $T M$ cảnh trong trái và đặt sẵn một kim luồn vào $\mathrm{TM}$ cảnh trong phải, tất cả được thực hiện vô trùng. BN được đặt tư thế nằm nghiêng trái $20-30^{\circ}$, hai tay xuôi theo thân người, đầu nghiêng về phía bên trái bộc lộ kim luồn đã được đặt sẵn. Phẫu thuật viên vẽ vị trí dự định đặt các lỗ trocar. 


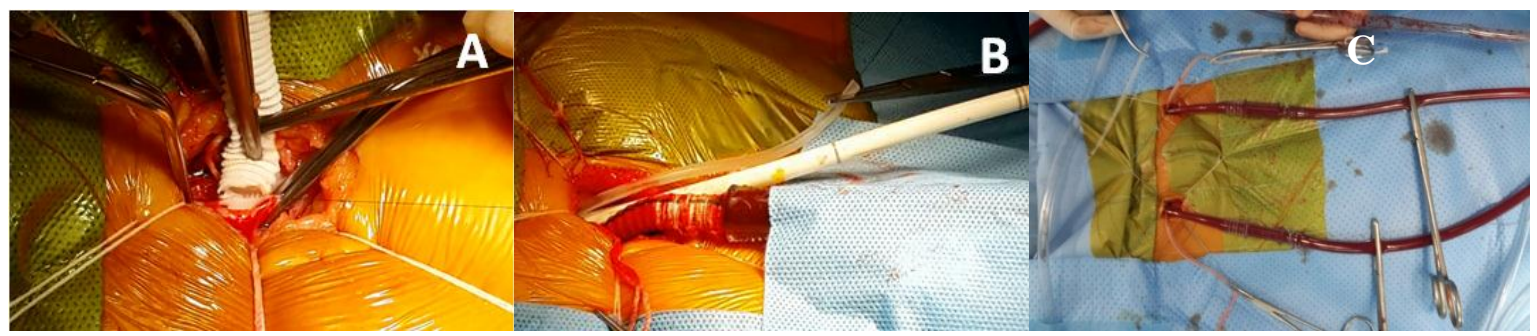

Hình 1, (A) Cannula ĐM đùi được thiết lập gián tiếp qua một đoạn mạch nhân tạo (Dacron hoạc PTFE), (B) TMC trên và TMC duới được dẫn luu qua TM cảnh trong phải và TM đùi theo kỹ thuật Seldinger và $(C)$ cannula ĐM đùi hai bên được đặt trục tiếp.

Để thiết lập tuần hoàn ngoại vi chúng tôi tạo một đường rạch dài $2 \mathrm{~cm}$ ngang ở nếp bẹn bên phải, bộc lộ $M$ đùi chung và $\mathrm{TM}$ đùi. Ở những $\mathrm{BN}$ có cân nặng $>15 \mathrm{~kg}$, chúng tôi thiết lập đường động mạch một cách gián tiếp vào ĐM đùi chung qua một đoạn mạch nhân tạo (mạch Dacron số 8 cho $\mathrm{BN}$ có cân nặng $\geq 30 \mathrm{~kg}$ và mạch Dacron số 6 cho những $\mathrm{BN}$ có cân nặng $<30 \mathrm{~kg}$ ). Cannula TMC trên và TMC dưới được đặt qua $\mathrm{TM}$ cảnh trong phải và $\mathrm{TM}$ đùi theo phương pháp Sheldinger. Trước khi đặt trocar, chúng tôi kiểm tra đường ĐM bằng cách chạy máy thử, nếu với toàn bộ lưu lượng áp lực đường $\mathrm{ĐM}<220 \mathrm{mmHg}$ là chấp nhận được. Nếu áp lực đường ĐM tăng quá $220 \mathrm{mmHg}$, chúng tôi đặt một đường ĐM phụ đùi bên trái với kích thước cannula nhỏ hơn $4 \mathrm{~F}$ so với chuẩn dựa theo cân nặng BN. Ở những $\mathrm{BN}$ nhỏ tuổi, cân nặng < $15 \mathrm{~kg}$, chúng tôi đặt cannula trực tiếp vào ĐM đùi hai bên, chủ động lựa chọn kích thước cannula nhỏ hơn $2-4 \mathrm{~F}$ so với chuẩn dựa theo cân nặng của $\mathrm{BN}$.

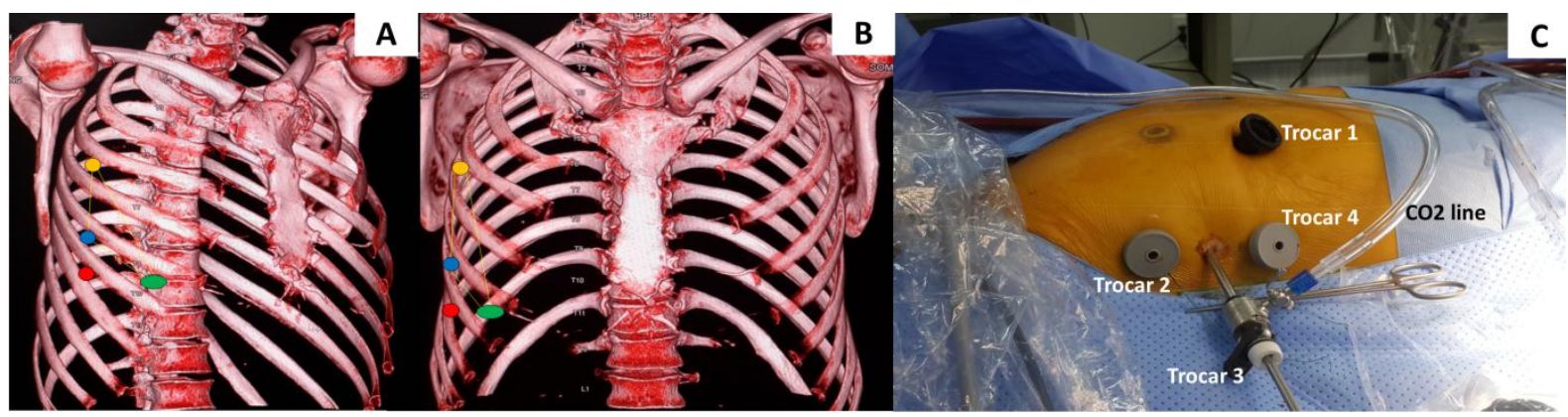

Hình 2, cách thức đặt 4 trocar. Mầu xanh lá cây (trocar 1 trong hình C) là vị trí tay làm việc chính đặt ở KLS V đương nách truớc. Mầu vàng (trocar 2 trong hình $C$ ) là vị trí tay làm việc phu đặt ở KLS III đường nách giũa. Mầu xanh da trời (trocar 3 trong hình C) là vị trí của camera đặt ở KLS V đuờng nách giữa. Mầu đỏ (trocar 4 trong hình C) là vị trí đường hút máu về đặt ở KLS VI đường nách giữa. 
Đặt 4 trocar tại các vị trí đã đánh dấu sẵn (hình 2), cụ thể là: 01 trocar 12mm tại khoang liên sườn (KLS) $\mathrm{V}$ đường nách trước là tay làm việc chính (cho các dụng cụ: phẫu tích, kìm kẹp kim, dao điện nội soi, hút bỏ), 01 trocar $5 \mathrm{~mm}$ tại KLS IV đường nách giữa là tay làm việc phụ (cho phẫu tích), 01 trocar $5 \mathrm{~mm}$ tại KLS $\mathrm{V}$ đường nách giữa (cho đèn nội soi) và 01 trocar $5 \mathrm{~mm}$ tại KLS VI đường nách giữa (cho đường hút máu về). Sau khi vào đến khoang màng phổi, hệ thống tuần hoàn ngoài cơ thể bắt đầu hoạt động, nhiệt độ thực quản được hạ dần xuống $32^{\circ} \mathrm{C}$, màng tim được mở song song và cách thành ngực trước $1.5-2 \mathrm{~cm}$.

Ngay khi thiết lập xong các trocar, $\mathrm{CO} 2$ được bơm vào khoang màng phổi với tốc độ 0,51/phút. Mở nhĩ phải (NP) dọc theo rãnh liên nhĩ sau khi đã thắt $\mathrm{TMC}$ trên và $\mathrm{BN}$ ở tư thế Trendelenburg. Tim đập liên tục trong suốt quá trình mổ, máu về qua xoang vành, các lỗ đổ trực tiếp trên thành $\mathrm{NP}$ và lỗ $\mathrm{TMC}$ dưới (TMC dưới không thắt). Để ngăn khí về qua cannula TMC dưới; đầu cannula TMC đưới được điều chỉnh sao cho nằm dưới van Eustachian 1,5-2cm. Ngăn máu từ TMC dưới đổ về $\mathrm{NP}$ bằng (1) hút âm đường $\mathrm{TM}$ với áp lực 20-40mmHg và (2) sử dụng một đường hút máu về để tạo phẫu trường sạch máu. Các mốc giải phẫu cần xác định trong quá trình mổ gồm: lỗ van ba lá, lỗ xoang vành, lỗ TMC dưới và các lỗ TMP phải. Lỗ thông được đóng bằng miếng vá nhân tạo hoặc khâu trực tiếp. TMP lạc chỗ được tạo đường hầm trong tim dẫn máu về nhĩ trái qua lỗ TLN. Những trường hợp van ba lá hở vừa - nhiều, phương pháp Devega được áp dụng cho những vòng van có đường kính ngang $<45 \mathrm{~mm}$, đặt vòng van ba lá được áp dụng cho những vòng van có đường kính ngang $\geq 45 \mathrm{~mm}$.

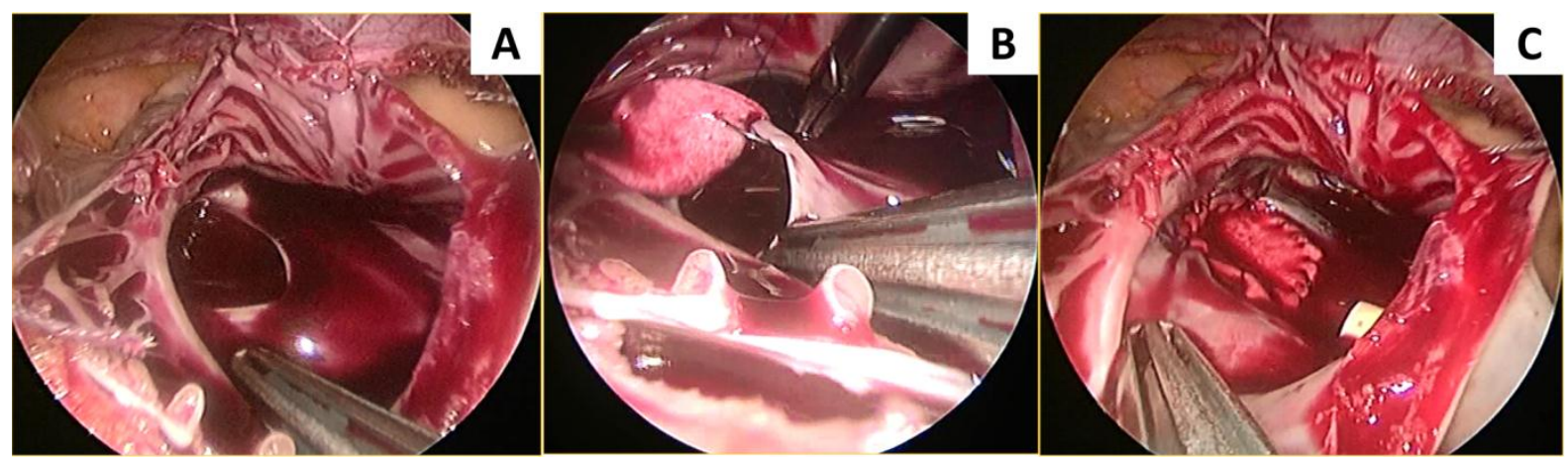

Hinh 3, Kỹ thuật vá TLN NSTB. (A) Nhĩ phải được mở sau khi làm đầy khoang màng phổi và màng tim bằng CO2, lỗ TLN thứ phát (mũi tên mầu trắng);(B): vá lỗ TLN sư dụng miếng vá nhân tạo, khâu vắt; (C): hoàn thành quá trình vá TLN.

Đường mở NP được đóng hai lớp. Tim được làm đầy sau khi thả thắt $\mathrm{TMC}$ trên, tư thế đầu bằng và kiểm tra cầm máu kỹ, màng tim được đóng mũi rời. Những $\mathrm{BN}>18 \mathrm{~kg}$ được siêu âm thực quản trong suốt quá trình vá TLN để theo dõi tình trạng khí trong thất trái, ĐMC cũng như tình trạng hoạt động của van ĐMC. Siêu âm giúp loại trừ shunt tồn lưu 
trước khi quyết định kết thúc cuộc mổ. Ngừng tuần hoàn ngoài cơ thể sau khi đặt 01 dẫn lưu màng tim và 01 dẫn lưu màng phổi. Quy trình còn lại giống như phẫu thuật nội soi lồng ngực đơn thuần. Tất cả BN sau mổ được kiểm tra bằng siêu âm qua thành ngực và siêu âm doppler mạch máu trước khi ra viện.

Bảng 2: Các thông số về thiết lập tuần hoàn ngoài cơ thể ngoại vi

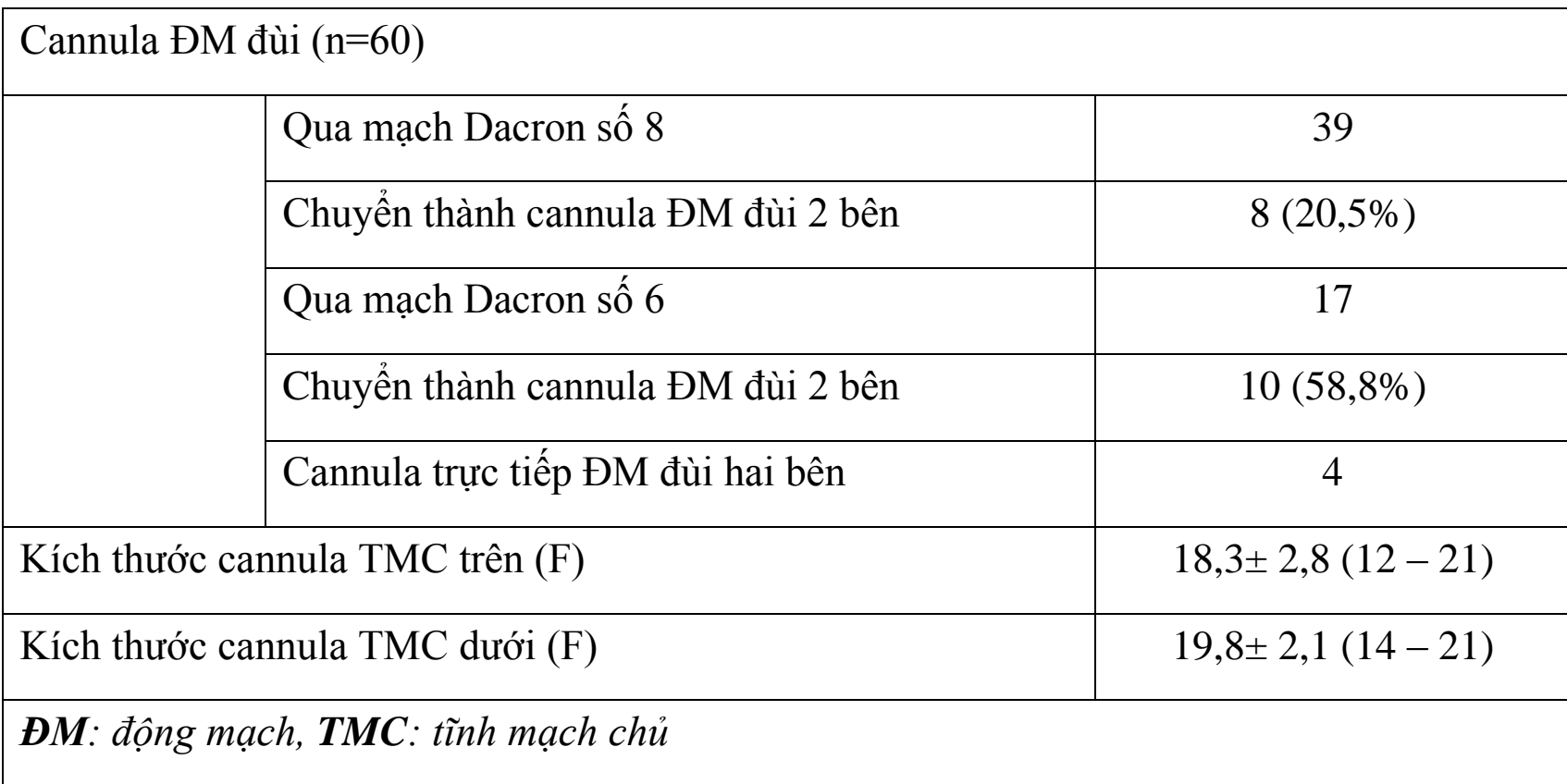

\subsection{Theo dõi sau mổ}

BN được hẹn khám lại sau mổ 1 tháng, 3 tháng, 6 tháng, 1 năm. BN được khám, đánh giá tình trạng sẹo mổ, sự cân đối giữa hai ngực, tình trạng dị cảm quanh vị trí vết mổ ngực và đùi, sự hài lòng của gia đình và $B N$ về vị trí và kích thước sẹo mổ. $\mathrm{BN}$ được siêu âm tim qua thành ngực và siêu âm doppler mạch kiểm tra.

\subsection{Phân tích số liệu}

Số liệu được tính ra trung bình \pm phương sai (S.D.) cho những biến định lượng và tính ra số lượng với tỉ lệ phần trăm cho những biến định tính. Số liệu được quản lý và phân tích bởi phần mềm SPSS 14.0.

\section{KẾT QUẢ}

Trong $60 \mathrm{BN}$ nghiên cứu, có $56 \mathrm{BN}$ được dự kiến thiết lập cannula ĐM đùi một bên qua đoạn mạch nhân tạo (39 BN sử dụng mạch Dacron số 8, 17 BN sử dụng mạch Dacron số 6). Trong đó $18 \mathrm{BN}$ phải chuyển thành cannula ĐM đùi 2 bên do áp lực đường $Đ M$ tăng cao hơn mức cho phép. Những $\mathrm{BN}$ sử dụng mạch Dacron số 8 và mạch Dacron số 6 có tỉ lệ chuyển thành cannula $Đ M$ đùi 2 bên lần lượt là $20,5 \%$ và $58,8 \%(\mathrm{p}=0,0048)$.Chi tiết về thiết lập tuần hoàn ngoài cơ thể được trình bày trong Bảng 2 . 
Bảng 3: Các thông số trong và sau mổ $(\mathrm{n}=60)$

\begin{tabular}{|l|l|l|l|}
\hline & \multicolumn{1}{|c|}{$\begin{array}{c}\text { Nhóm A } \\
\mathbf{1 - 3 5}\end{array}$} & \multicolumn{1}{|c|}{$\begin{array}{c}\text { Nhóm B } \\
\mathbf{3 6 - 6 0}\end{array}$} & \multicolumn{1}{|c|}{ P value } \\
\hline Thời gian mổ (phút) & $254,9 \pm 43,0$ & $201,4 \pm 54,9$ & 0,000068 \\
\hline Thời gian chạy máy (phút) & $157,8 \pm 35,2$ & $92,7 \pm 33,2$ & 0,0000000015 \\
\hline Thời gian thiết lập THNCT (phút) & $46,4 \pm 13,1$ & $43,5 \pm 11,7$ & 0,24 \\
\hline Thời gian bộc lộ lỗ TLN (phút) & $26,0 \pm 5,2$ & $21,3 \pm 7,9$ & 0,013 \\
\hline Thời gian vá TLN (phút) & $51,3 \pm 18,7$ & $23,5 \pm 10,9$ & 0,00000022 \\
\hline Thời gian đóng NP (phút) & $20,0 \pm 6,8$ & $15,9 \pm 7,0$ & 0,023 \\
\hline Thời gian sửa VBL (phút) & $15.4 \pm 11,5$ & $16,8 \pm 10,5$ & 0,41 \\
\hline Thời gian thở máy (giờ) & $9,4 \pm 16,3$ & $7,2 \pm 5,3$ & 0,27 \\
\hline Thời gian nằm hồi sức (giờ) & $25,1 \pm 22,4$ & $29,8 \pm 28,4$ & 0,25 \\
\hline Dẫn lưu trong 24 giờ đầu (ml) & $96,6 \pm 68,4$ & $57,7 \pm 43,5$ & 0,011 \\
\hline $\begin{array}{l}\text { Thời điểm không cần dùng thuốc } \\
\text { giảm đau sau mồ (ngày) }\end{array}$ & $4,2 \pm 1,3$ & $4,1 \pm 1,0$ & 0,44 \\
\hline Thời gian nằm viện sau mổ (ngày) & $9,1 \pm 2,9$ & $7,9 \pm 5,3$ & 0,15 \\
\hline Biến chứng thần kinh và mạch đùi & 0 & 0 & \\
\hline TLN tồn lưu nhỏ & 1 & 0 & \\
\hline
\end{tabular}

Thời gian phẫu thuật và thời gian chạy máy trung bình lần lượt là $234,2 \pm 54,3$ phút và $132,0 \pm 46,9$ phút. Tất cả $\mathrm{BN}$ không cần dùng thuốc vận mạch sau ngừng hệ thống THNCT và được rút máy thở trong vòng 8 giờ. Không có $\mathrm{BN}$ nào có biến chứng về thần kinh sau mổ. Sau 4 ngày BN không cần dùng thuốc giảm đau, người bệnh có thể trở lại sinh hoạt bình thường sau mổ 7 ngày.

Chúng tôi chia $\mathrm{BN}$ thành 2 nhóm thuộc hai giai đoạn; nhóm $\mathrm{A}$ gồm $35 \mathrm{BN}$ đầu tiên và nhóm $\mathrm{B}$ gồm $25 \mathrm{BN}$ sau đó. Các thông số trong và sau mổ của hai nhóm được so sánh trong bảng 3 . Thời gian mổ và thời gian chạy máy của nhóm $\mathrm{B}$ ngắn hơn một cách có ý nghĩa so với nhóm $\mathrm{A}$ với giá trị $\mathrm{p}$ lần lượt là 0,000068 và 0,0000000015 . Thời gian của các thì phẫu thuật ở nhóm $\mathrm{B}$ đều được rút ngắn so với nhóm $\mathrm{A}$, trong đó thời gian vá TLN được rút ngắn một cách có ý nghĩa nhất $(\mathrm{p}=0,00000022)$.Kết quả sau mổ và tỉ lệ gặp biến chứng ở hai nhóm không có sự khác biệt (bảng 4).

Một trường hợp tồn lưu TLN với đường kính $3 \mathrm{~mm}$ trên siêu âm thực quản, kích thước lỗ thông nhỏ đi sau 1năm khám lại. Tất cả BN và gia đình đều rất hài lòng về hiệu quả và tính thẩm mỹ của sẹo mổ.

\section{BÀN LUẬn N}

Từ cuối những năm 1990 đến nay, nhiều 
báo cáo về phẫu thuật NSTB có sự hỗ trợ của hệ thống robot Da Vinci trong điều trị bệnh TLN với kết quả thành công rất cao với rất ít biến chứng.[5, 7] PT nội soi sử dụng công nghệ robot giúp khuyếch đại tối đa các cấu trúc trong tim, đồng thời dụng cụ nội soi thông qua các tay robot có độ linh hoạt rất cao giúp phẫu thuật viên dễ dàng tiếp cận những phẫu trường sâu và xử lý được những thương tổn trong không gian chật hẹp. Mặc dù vậy, chi phí cao là rào cản lớn khiến phẫu thuật robot không được áp dụng rộng rãi, đặc biệt ở các nước đang phát triển.[8]

Phẫu thuật tim đập giúp tránh tình trạng thiếu máu cơ tim và hiện tượng tái tưới máu sau mổ.[9] Mặc dù vậy, có rất ít báo cáo về PT NSTB trong điều kiện tim đập để vá TLN vì: (1) nguy cơ tắc mạch khí và (2) khó thao tác do phẫu trường nhiều máu.[10]Theo Mo cùng cộng sự, tắc mạch khí xảy ra khi khí có mặt trong thất trái và áp lực áp lực trong thất trái cao hơn áp lực trong gốc ĐMC.[9]Một số nguyên tắc phòng tắc mạch khí được các tác giả nhắc đến, bao gồm: duy trì áp lực trung bình đường $Đ M>60$ hoặc $70 \mathrm{mmHg}$ ở người lớn và $>50 \mathrm{mmHg}$ ở trẻ nhỏ $[9,11]$, giữ cho nhĩ trái và thất trái ở trạng thái đầy máu[12], làm đầy khoang màng tim và màng phổi bằng $\mathrm{CO} 2[11,13]$ và đuổi khí bằng bóp bóng trước khi hoàn thành đường khâu đóng TLN.[10] $\mathrm{CO} 2$ đã được chứng minh có vai trò thay thế phương pháp đuổi khí truyền thống nhờ chiếm chỗ không khí trong phẫu trường và khả năng tan trong nước tốt.[4] $\mathrm{CO} 2$ làm tan các bóng khí trong tim và rút ngắn thời gian đuổi khí 3 lần so với phương pháp truyền thống. Thêm vào đó, việc sử dụng $\mathrm{CO} 2$ trong phẫu thuật tim đập đã được chứng minh không gây bất kỳ vấn đề thần kinh nào.[11]Chúng tôi phòng tắc mạch khí dựa trên 2 nguyên tắc chính: (1) duy trì áp lực đường $\mathrm{ĐM}$ cao và (2) làm đầy khoang màng tim màng phổi bằng $\mathrm{CO} 2$. Siêu âm thực quản trong mổ cho thấy không có khí trong thất trái cũng như ĐMC lên, van ĐMC hầu như luôn đóng trong suốt quá trình vá TLN; sau mổ chúng tôi không ghi nhận trường hợp có biến cố thần kinh.

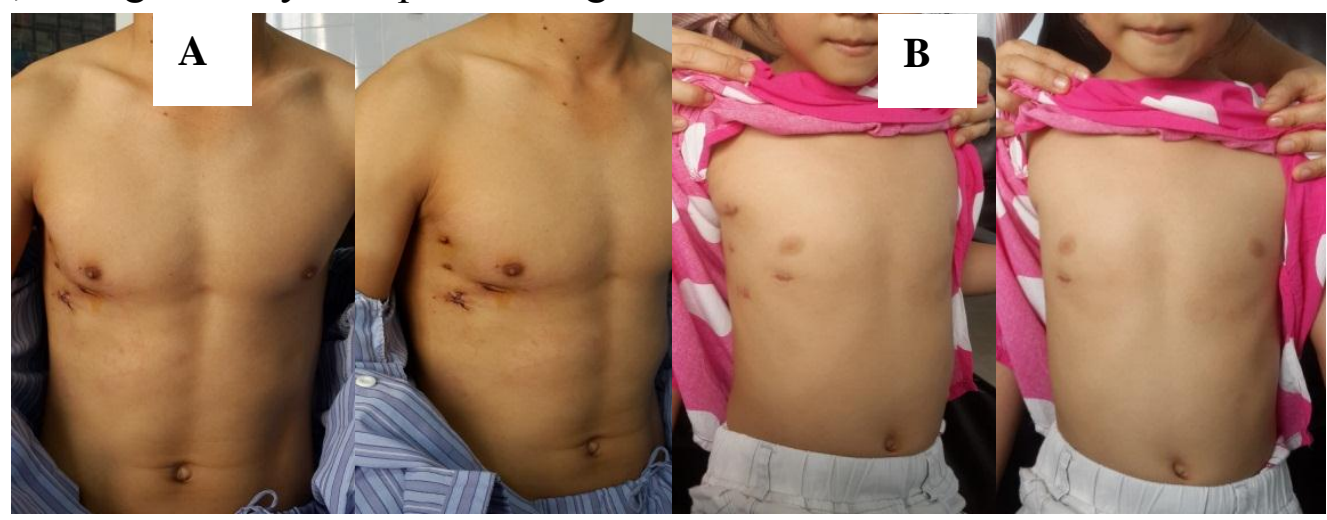

Hình 4. Kết quả sau mổ NSTB không có robot hỗ trọ, tim đập. BN nam 24 tuổi ngay sau mổ;(B) BN nũ 7 tuổi sau mổ 1 tháng 
Thiếu máu chi dưới cấp và hẹp mạch sau mổ là những biến chứng nặng của phẫu thuật nội soi tim, đặc biệt hay gặp ở trẻ nhỏ. Bằng việc cannula ĐM đùi gián tiếp qua đoạn mạch nhân tạo và sử dụng cannula ĐM đặt trực tiếp có kích thước nhỏ hơn 2-4F so với chuẩn dựa theo cân nặng của $\mathrm{BN}$ giúp tránh được những biến chứng kể trên. Trong nghiên cứu này, chúng tôi có $11 \mathrm{BN} \leq 7$ tuổi, với thời gian theo dõi từ 3 tháng đến 13 tháng không gặp biến chứng về mạch máu ngoại vi. Áp lực đường $\mathrm{ĐM}$ tăng cao (do khẩu kính nhỏ và tính chất co thắt của thành mạch) là một trong những nguyên nhân gây thất bại nội soi. Cannula ĐM hai bên là giải pháp cứu cánh trong những trường hợp này.[14] Trong nghiên cứu này, chúng tôi ghi nhận tỉ lệ chuyển từ cannula $\mathrm{ĐM}$ đùi một bên thành hai bên ở $\mathrm{BN}$ có cân nặng thấp cao hơn một cách có ý nghĩa so với những $\mathrm{BN}$ có cân nặng lớn $(\mathrm{p}=0,0048)$.

Cách thức thiết lập trocar của chúng tôi tương tự cách thiết lập trocar trong PT có robot hỗ trợ.[4] Bonaros [7] và $\mathrm{Ma}$ [8]thấy rằng khi kinh nghiệm của phẫu thuật viên tăng lên thì thời gian phẫu thuật sẽ được rút ngắn lại. Trong nghiên cứu của chúng tôi, tất cả $\mathrm{BN}$ được phẫu thuật bởi 1 tác giả duy nhất; chúng tôi cũng ghi nhận một đường cong đào tạo (learning curve) rất rõ với các khoảng thời gian phẫu thuật được rút ngắn rất đáng kể (bảng 3 ).

\section{KẾT LUẬN}

Phương phápPT NSTB vá TLN không có robot hỗ trợ, tim đập là phương pháp an toàn, hiệu quả, hứa hẹn có thể triển khai rộng trong tương lai gần góp phần nâng cao chất lượng điều trị bệnh TBS.

\section{TÀI LIỆ THAM KHẢO}

1. M. A. Ostovan, J. Kojuri, P. Dehghani và các cộng sự. (2016), "Device closure in adults with atrial septal defect in Shiraz, a single center registry", J Cardiovasc Thorac Res, 8(1), tr. 40-2.

2. Z. Jalal, S. Hascoet, A. E. Baruteau và các cộng sự. (2016), "Long-term Complications After Transcatheter Atrial Septal Defect Closure: A Review of the Medical Literature", Can J Cardiol.

3. U. Krumsdorf, S. Ostermayer, K. Billinger và các cộng sự. (2004), "Incidence and clinical course of thrombus formation on atrial septal defect and patient foramen ovale closure devices in 1,000 consecutive patients", J Am Coll Cardiol, 43(2), tr. 302-9.

4. C. Xiao, C. Gao, M. Yang và các cộng sự. (2014), "Totally robotic atrial septal defect closure: 7-year single-institution experience and follow-up", Interact Cardiovasc Thorac Surg, 19(6), tr. 933-7.

5. J. A. Morgan, J. C. Peacock, T. Kohmoto và các cộng sự. (2004), "Robotic techniques improve quality of life in patients undergoing atrial septal defect repair", Ann Thorac Surg, 77(4), tr. 1328-33.

6. C. Gao, M. Yang, G. Wang và các cộng sự. (2010), "Totally endoscopic robotic 
atrial septal defect repair on the beating heart", Heart Surg Forum, 13(3), tr. E155-8.

7. N. Bonaros, T. Schachner, A. Oehlinger và các cộng sự. (2006), "Robotically assisted totally endoscopic atrial septal defect repair: insights from operative times, learning curves, and clinical outcome", Ann Thorac Surg, 82(2), tr. 687-93.

8. Z. S. Ma, M. F. Dong, Q. Y. Yin và các cộng sự. (2011), "Totally thoracoscopic repair of atrial septal defect without robotic assistance: a single-center experience", $J$ Thorac Cardiovasc Surg, 141(6), tr. 1380-3.

9. A. Mo, H. Lin, Z. Wen và các cộng sự. (2008), "Efficacy and safety of on-pump beating heart surgery", Ann Thorac Surg, 86(6), tr. 1914-8.

10. Z. S. Ma, M. F. Dong, Q. Y. Yin và các cộng sự. (2012), "Totally thoracoscopic closure for atrial septal defect on perfused beating hearts", Eur J Cardiothorac Surg, 41(6), tr. 1316-9.

11. K. Chaudhuri, E. Storey, G. A. Lee và các cộng sự. (2012), "Carbon dioxide insufflation in open-chamber cardiac surgery: a double-blind, randomized clinical trial of neurocognitive effects", J Thorac Cardiovasc Surg, 144(3), tr. 646-653 e1.

12. S. Thapmongkol, J. Sayasathid, J. Methrujpanont và các cộng sự. (2012), "Beating heart as an alternative for closure of secundum atrial septal defect", Asian Cardiovasc Thorac Ann, 20(2), tr. 141-5.

13. M. Landenhed, F. Al-Rashidi, S. Blomquist và các cộng sự. (2014), "Systemic effects of carbon dioxide insufflation technique for de-airing in left-sided cardiac surgery", J Thorac Cardiovasc Surg, 147(1), tr. 295-300.

14. C. Rosu, D. Bouchard, M. Pellerin và các cộng sự. (2015), "Preoperative vascular imaging for predicting intraoperative modification of peripheral arterial cannulation during minimally invasive mitral valve surgery", Innovations (Phila), 10(1), tr. 39-43.

TOTALLY ENDOSCOPIC SURGERY FOR ATRIAL SEPTAL DEFECT REPAIR ON BEATING HEART WITHOUT ROBOTIC ASSISTANCE:

A SINGLE-CENTER EXPERIENCE

Dang Quang Huy*, Le Ngoc Thanh

Cardiovascular and Thoracic Surgery

Department, Cardiovascular Center, 87-89

Tran Cung, Cau Giay, Dong Da, Hanoi

* Corresponding author.

Tel: +84982024618.

Email: drdangquanghuy@gmail.com

Objectives: Totally endoscopic surgery (TES) has not been applied much for the treatment of congenital heart diseases (CHD). In this study, we evaluate the safety and efficacy of the application of TES on the beating heart, without the assistance of robotic system for the treatment of atrial septal defect (ASD).

Subjects and study method: 60 patients (adults/children: 41/19; mean age: $29.1 \pm 18.7$, ranged from 2 to 61 years old) diagnosed with secundum ASD were enrolled in our study. 
There were 38 patients with isolated ASD, 4 patients had concomitant partial anomalous pulmonary venous return, 17 patients had ASD associated with severe tricuspid regurgitation. Peripheral extracorporeal circulation was established. Three $5 \mathrm{~mm}$ trocars and one $12 \mathrm{~mm}$ trocar were placed, only the superior vena cava (SVC) was snared, the pleural space was filled with $\mathrm{CO} 2$, the heart was beating during surgery. The defect was closed by an artificial patch, continuous suture, the anomalous pulmonary veins were drained to left atrium by constructing a tunnel, tricuspid valve repair using annular ring placement or De Vega method.

\section{Results:} No surgery-related complications or death was noted. Mean operation time and cardiopulmonary bypass time were $234.2 \pm 54.3$ (minutes) and $132 \pm$ 46.9 (minutes), respectively. Patients were extubated within the first 4 hours postoperation, the volume of blood drainage in the first day was less than $80 \mathrm{ml}$. Four days after surgery, patients did not need any analgesics and can return to normal daily activities 1 week postoperatively.

Conclusion: TES for ASD closure on the beating heart is safe, patients recovered quickly, surgical scars were of high aesthetic value, especially in women and young girls.

Keywords: Atrial septal defect, totally endoscopic surgery, beating heart, robot. 